\title{
EL SISTEMA ESCOLAR DE LA CIUDAD DE VALENCIA EN EL SIGLO XV
}

\section{THE SCHOOL SYSTEM IN THE CITY OF VALENCIA IN THE $15^{\text {TH }}$ CENTURY}

José María Cruselles

Universitat de València

\section{RESUMEN}

En la Valencia de finales de la Edad Media existió una reducida inserción de la enseñanza de las letras en el mundo del aprendizaje doméstico. Para las familias acomodadas, la escuela de gramática era la prolongación de la enseñanza doméstica allí donde no alcanzaba la competencia paterna. La Iglesia era la única institución que, hasta finales del siglo XIV, contaba con los medios y el personal necesario para mantener escuelas. A partir de 1373, la intervención municipal puso fin al monopolio eclesiástico. Durante el siglo XV coexistieron las escuelas subvencionadas por la Iglesia y por el municipio, junto con otras independientes.

Paraules clau: Escuelas medievales. Historia de la cultura. Historia de la Educación. Ciudad medieval. Sociedad urbana medieval.

\begin{abstract}
In Valencia there was during the late Middle Ages a reduced insertion of the teaching of humanities in the world of home schooling. For wealthy families, the school of grammar was the extension of home schooling there where the paternal competence did not reach. The Church was the only institution that, until the end of the 14th century, had the necessary means and staff to maintain schools. From 1373, municipal intervention put an end to the ecclesiastical monopoly. During the 15th century the schools subsidised by the Church and by the municipality coexisted, along with other independent ones.
\end{abstract}

Keywords: Medieval Schools. Cultural History. History of Education. Medieval City. Medieval Urban Society. 


\section{RESUM}

En la València de finals de l'Edat Mitjana existí una reduïda inserció de l'ensenyament de les lletres en el món de l'aprenentatge domèstic. Per a les famílies benestants, l'escola de gramàtica era la prolongació de l'ensenyament domèstic allí on no arribava la competència paterna. L'església era l'única institució que, fins finals del segle XIV, comptava amb els mitjans i personal necessari per a mantenir escoles. A partir de 1373 la intervenció municipal posà fi al monopoli eclesiàstic. Durant el segle XV coexistiren les escoles subvencionades per l'esglèsia i pel municipi, juntament amb altres d'independents.

Paraules clau: Escoles medievals, història de la cultura, història de l'educació, ciutat medieval, societat urbana medieval. 
En los últimos tiempos de la Edad Media coexistían en la ciudad de Valencia, como en tantas otras de Europa Occidental, dos sistemas educativos que, aun manteniendo ciertas interacciones, se sustentaban en procedimientos, programas y objetivos netamente diferenciados. El aprendizaje doméstico integraba a la gran mayoría de los niños y jóvenes, tanto de la propia ciudad como del campo circundante. Para los habitantes del entorno rural constituía uno de los mecanismos que sustentaban el movimiento migratorio y la integración laboral de una parte importante de la sociedad campesina en la producción manufacturera urbana. ${ }^{1}$ Las ordenanzas municipales, en respuesta a las necesidades e iniciativas del mundo corporativo, habían regulado progresivamente la incorporación de niños y adolescentes a los talleres y casas de los maestros artesanos. Por el contrario, el otro sistema educativo, el que conducía a las escuelas de letras y las universidades, se encontraba por esa misma época en un estado de casi completa desarticulación normativa. Desde el último cuarto del siglo XIV y hasta la fundación de la Universidad de Valencia en 1499, los proyectos reguladores emprendidos por el municipio arrojaron sonoros fracasos 0 , como mucho, resultados mediocres. ${ }^{2}$

1 Abreviaturas: ARV (Archivo del Reino de Valencia), ACCV (Archivo del Colegio del Corpus Christi de Valencia), AMV (Archivo Municipal de Valencia).

Acerca de la movilidad geográfica asociada al aprendizaje laboral en la Valencia de fines de la Edad Media, véanse RUBIO, Agustín (1990), "Infancia y marginación. En tomo a las instituciones trecentistas valencianas para el socorro de los huérfanos", Revista d'Historia Medieval, 1, pp. 137-139; y SIXTO, Ricardo (1993), La contratación laboral en la Valencia medieval: aprendizaje y servicio doméstico (1458-1462), tesis de licenciatura, Universidad de Valencia. Una valoración relativa de los datos en CRUSELLES, Enrique (1999), "La población de la ciudad de Valencia en los siglos XIV y XV", Revista d'Història Medieval, 10, pp. 45-84, y especialmente p. 64, nota 40.

2 Un estudio detallado del intervencionismo educativo municipal en CRUSELLES, José $M^{a}$ (1997), Escuela y sociedad en la Valencia medieval, Diputación de Valencia, Valencia, pp. 41-69; CRUSELLES, José $M^{a}$ (1993), "La política educativa del Consell de València antes de la fundación de la Universidad", Pedralbes. Revista d'Història Moderna, 13:2, pp. 387-394. 


\section{LA eNSEÑ̃NZA de LAS LetraS EN El MUNDO LABORAL URBANO}

Aprendizaje laboral y educación escolar constituían sistemas de enseñanza aparentemente incompatibles. El primero suponía extrañamiento de la casa paterna, domesticidad del trabajo respecto a la casa y taller del patrón, y era eminentemente práctico en cuanto a sus contenidos y procedimientos. La segunda, por el contrario, no requería abandonar la casa paterna, aunque tenía lugar en un ámbito extra-doméstico, la escuela, y su fundamento pedagógico era la memorización de textos. Mediante los llamados contratos de afermament, que constituían el instrumento básico para regular el mercado laboral infantil y juvenil, los padres o tutores legales enviaban a niños y niñas de entre seis y diez años de edad normalmente, a casa de un patrón que tenía el deber de proporcionarles alojamiento, alimento y vestido a cambio de un genérico servicio doméstico. En el caso de los varones, a quienes este procedimiento convertía en aprendices, el patrón solía ser un maestro artesano que asumía dos particulares obligaciones: enseñarles su oficio y comprarles ropas nuevas cuando terminara el periodo acordado de servicio. De este modo, el macip pasaba a integrarse en un nivel subalterno dentro de la familia y, sobre todo, el taller de su patrono. Esta cláusula de aprendizaje no era habitual en los contratos que afectaban a las niñas, quedando sustituida por el pago de una soldada en metálico que solía hacerse también al final del periodo. La macipa era una joven criada doméstica cuyo tiempo de servicio conducía frecuentemente al matrimonio, pues le permitía reunir una parte importante si no la totalidad de su dote.

El aprendizaje laboral y el servicio doméstico constituían el sistema normalizado de reconvertir el tiempo de la infancia y de la adolescencia en capacitación laboral para los varones y medios de acceso al matrimonio para las mujeres. Por su parte, los patronos encontraban un procedimiento barato de abastecer sus casas y talleres de mano de obra no cualificada. ${ }^{3}$ Para los padres no solo era una manera eficaz de restar cargas a una economía familiar precaria o simplemente modesta, sino también de facilitar la movilidad laboral y geográfica de sus hijos, cambiando la profesión paterna por otra distinta y más provechosa, o trasladándolos del campo a

3 Las ventajas económicas evidentes que el sistema reportaba a los patronos ha llevado a algunos autores a considerar que su verdadera finalidad no era tanto asegurar el aprendizaje laboral de los jóvenes dentro del mundo corporativo, como transferir fuerza de trabajo desde las unidades familiares y productivas más débiles y peor situadas hacia las más solventes, marcando un límite nítido dentro de la jerarquía socioeconómica del mundo artesanal, IRADIEL, Paulino (1989), El segle XV. L'evolució económica, en Història del País Valencià, vol. 2, Edicions 62, Barcelona, pp. 318-319. 
la ciudad. ${ }^{4}$ Por último, para las autoridades municipales y corporativas era una forma aceptable de controlar el acceso al mercado laboral y la competencia, razón por la que procuraron regular el afermamenty establecer con detalle los derechos y obligaciones de las partes, así como los mecanismos para resolver los conflictos de intereses que pudieran surgir entre ellas.

Sus quehaceres diarios mantenían al aprendiz en la casa y sobre todo en el taller, que era por definición el espacio educativo-laboral que le correspondía. La asistencia a la escuela estaba descartada, pues no eran muchos los patrones dispuestos a prescindir de una parte del trabajo de sus aprendices para escolarizarlos. Sin embargo, contamos con indicios de la existencia de una cierta aunque muy reducida penetración de la enseñanza de las letras en el mundo del aprendizaje y el servicio doméstico masculino. Apenas una veintena de contratos datados entre finales del siglo XIV y mediados del XV, que presentan una interesante diferencia respecto al común de los afermaments: el patrón se comprometía a proporcionar a su macip un aprendizaje literario limitado. ${ }^{5}$ Las fórmulas utilizadas por los notarios para describir dicha obligación pueden hacernos pensar que eran los propios patronos quienes asumían en persona las tareas docentes, utilizando para ello los materiales didácticos más sencillos, como la tabla y el salterio. ${ }^{6}$ En ocasiones pudo ser así, ya que el calendario laboral estaba cuajado de fiestas: una tercera parte del año, si nos atenemos a la enumeración hecha entre 1489 y 1491 por los arrendatarios de la escribanía de la Gobernación de Valencia.7 Además, algunos patronos estaban particularmente capacitados para ello, como era el caso de notarios y escribanos, aunque también de mercaderes y botiguers. Al contrario de lo que ocurría en Génova y Venecia, los notarios valencianos nunca mostraron interés en

4 Un buen ejemplo de las consideraciones que podían conformar las decisiones de padres o tutores lo encontramos en un afermament setabense de 1430, por el que un labrador de I'Olleria, que dos años antes había tomado como aprendiz a un huérfano de unos siete años llamado Joan, colocó a éste como macip con otro patrón, un jubonero de Xàtiva, durante los cuatro años que restaban por cumplir del contrato original, comprometiéndose a intentar que el tutor del niño ampliara el periodo a otros cuatro años más. Todo ello para que Joan, a quien el labrador había tomado afecto, pudiera aprender un oficio más provechoso que el de agricultor: (...) cum ego, dictus Dominicus Garcia, sum laborator et sit utilius dicto Johanni, attenta sui provitate, quod addiscat et sit seu exerceat officium maioris quittis quam esse laboratore (ACCV, Protocolos, 26551, not. Francesc Saranyana, 27 de enero 1430).

5 Un análisis más detallado de estos contratos en CRUSELLES, Escuela y sociedad, pp. 178-183.

6 Sobre los materiales pedagógicos utilizados en el primer aprendizaje de la lectura, véase LUCCHI, Piero (1978), "La Santacroce, il Salterio e il Babuino. Libri per imparare a leggere nel primo secolo della stampa", Quaderni Storici, 38, pp. 593-630.

7 CRUSELLES José $M^{a}$, La familia de Antoni Lopiç, notario de la ciudad de Valencia (14331493): promoción social de un profesional de la escritura, Tesis de licenciatura, Universidad de Valencia, 1985, p. 160. 
compaginar su profesión con la enseñanza de las letras, quizás porque no necesitaban complementar de ese modo sus ingresos; ${ }^{8}$ pero en algunos casos aceptaban la tarea de enseñar a leer y escribir a los niños que contrataban como sirvientes domésticos, nunca a las niñas, cuya remuneración se hacía siempre en metálico. Sabemos también que algunos artesanos asumieron esa misma obligación, aunque no parece probable que tal enseñanza llegara muy lejos, dada sus escasas competencias docentes y las dificultades que presentaba el propio medio en que debían ejercitarlas, el taller artesanal. Esta circunstancia puede advertirse en algunos contratos de afermament que especifican que el patrón debía enseñar a leer y escribir a su aprendiz "en la media en que pudiera aprender" (prout addiscere poterit). ${ }^{9}$ En ocasiones se indicaba expresamente que el patrono podía satisfacer las necesidades docentes de sus aprendices recurriendo a terceros. Así, un corredor que en 1420 contrató a su hijo como sirviente del zapatero Gil Gomis, quería que otros aprendices de este último le enseñaran a leer: "que el niño o los niños que tenéis en vuestra casa, que saben leer, le enseñen las letras". ${ }^{10}$

Enviar al macip a la escuela era la última de las opciones, porque el patrono no solo perdía fuerza laboral, sino que debía asumir también los correspondientes gastos. Conocemos dos contratos de afermament que contemplan esta circunstancia, aunque en términos generales resultan bastante excéntricos respecto al mundo del aprendizaje doméstico. En el primer caso el patrono era un maestro de escuela, Joan d'Ordós, a quien nos referiremos más adelante, y el aprendiz un hijo del difunto pañero Bartomeu Roig. La madre corría con los gastos de escolarización y alojamiento, que fueron establecidos en catorce libras valencianas al año, una cantidad respetable en aquella época. El joven viviría a partir de entonces en la casa-escuela del maestro "para aprender ciencia y hacer cuanto corresponde a un estudiante". ${ }^{11}$ No se trataba, evidentemente, de un contrato de traba-

8 La mediocridad económica que aquejaba en Venecia el ejercicio de la notaría, resultado de la multiplicación del número de notarios, empujaba a estos profesionales a la docencia de las letras, según señala ORTALLI, Gherardo (1993), Scuole, maestri e istruzione di base tra Medioevo e Rinascimento, Neri Pozza, Vicenza, p. 87.

9 En este caso, el maestro artesano era el barbero Mateu de Térmens en un contrato realizado con el padre de huérfanos de la ciudad de Valencia en 1409 (ARV, Protocolos, 3025; not. Vicent Saera, 15 de febrero 1409).

10 (...) facere ipsum docere litteras ab illo vel illis pueris quos tenetis in domo vestra qui sciunt legere (ARV, Protocolos, 2421; not. Vicent Saera, 7 de mayo de 1420).

11 (...) ad addiciendum scienciam et ad faciendum omnia que pertinet studenti (ARV, Protocolos, 791; not. Martí Doto, 29 de diciembre 1430). 
jo, sino del alojamiento de un escolar dentro del propio centro educativo, una práctica corriente en la época. En el segundo caso, el patrono era un sastre que daría alojamiento al huérfano de un compañero de profesión, a quien también debía escolarizar; pero de nuevo era la familia del macip la que asumía todos los gastos, que ascendían a doce libras anuales. $\mathrm{Si}$ consideramos que, además, no se contemplaba la prestación por parte del joven de ningún tipo de servicio doméstico, ni pago en metálico o entrega final de ropas por parte del patrón, podemos concluir que en este caso particular la fórmula contractual del afermament estaba siendo utilizada con propósitos ajenos propiamente al mundo del trabajo y más relacionados con solidaridades familiares, profesionales o vecinales. ${ }^{12}$

Cuando los afermaments incluían la enseñanza literaria entre los deberes del patrono, lo que ocurría escasamente y solo con macips varones, aquella podía venir unida o no al aprendizaje del oficio. En el primer caso la enseñanza laboral era predominante y las letras ocupaban un lugar accesorio dentro del conjunto de las obligaciones del patrón, que solía ser un artesano. Por lo que respecta a sus términos y condiciones, este tipo de contratos era en todo similar al resto de los afermaments masculinos de la época, con la única salvedad de que añadían aquella particular cláusula educativa. Sin embargo, cuando el patrón no asumía la tarea de enseñar su oficio, la instrucción literaria se convertía en la principal y a veces la única retribución del macip, pues no se le pagaba salario alguno-como era imprescindible en los afermaments femeninos- $y$ en algunos casos hasta desaparecía la entrega final de ropas. También cambiaba la condición de los patronos. Las ocupaciones artesanales dejaban paso a otras más propias de los grupos medios urbanos: notarios, escribanos, mercaderes y tenderos. Podemos afirmar, en consecuencia, que el objetivo de los padres y tutores que acordaban condiciones de este tipo no era que los niños se integraran en la manufactura, sino que adquirieran unos conocimientos que consideraban necesarios para optar a ocupaciones mejor valoradas socialmente, como el clero y la práctica notarial. También llama la atención que los patronos que ofrecían a sus macips exclusivamente enseñanza literaria, solían practicar profesiones en las que aprendizaje y servicio doméstico estaban cada vez más desvinculados funcionalmente. Los aprendices se reclutaban casi por completo dentro de la propia familia o de otras de similar condición socioeconómica con las que el patrono mantenía relaciones de parentesco, amistad o compañerismo corporativo; y a la hora de contratar 
servicio doméstico se prescindía habitualmente de los varones, sustituidos por niñas y muchachas cuya retribución se fijaba siempre en dinero. ${ }^{13}$

A partir de los contratos de aprendizaje sicilianos de esta época, Henri Bresc sugiere la naturaleza más democrática de la enseñanza literaria que se impartía en las casas-talleres de los patronos artesanos, porque las escuelas urbanas exigían desembolsos que no estaban al alcance de cualquiera. ${ }^{14}$ Sin embargo, este fenómeno tuvo un alcance social muy limitado. La preferencia que mercaderes y notarios mostraban por el servicio doméstico femenino da cuenta de la revalorización que la enseñanza literaria estaba adquiriendo frente al trabajo juvenil no cualificado y sobreabundante. De hecho, la inclusión de la enseñanza de las letras en el sistema del afermament masculino no parece haber arrojado resultados muy brillantes. Como mucho, pudo servir para promocionar puntualmente a algún hijo de artesano o agricultor hasta los niveles más bajos del clero. Sin duda, como señalaba Bresc, el sistema escolar bajomedieval respondía a las necesidades de los grupos medios y altos de la sociedad urbana, y contribuyó en poco a la educación de las clases subalternas; pero tampoco los mecanismos del afermament, adaptados al mundo del trabajo manual, mejoraron mucho la situación.

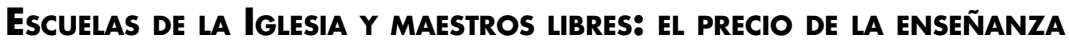

Las familias acomodadas mantenían a sus hijos apartados del mercado del afermament. En estos ambientes, el principal espacio educativo y laboral era la casa paterna. Sabemos que en algunas ciudades de Italia era corriente, entre los grupos burgueses, que las madres se hicieran cargo de mostrar a sus retoños los rudimentos del sistema lecto-escriturario como paso previo al ingreso en la escuela. ${ }^{15}$ No disponemos de indicios documentales que nos permitan asegurar que en Valencia se cumplía esta misma práctica, pero no cabe duda de que las escuelas que vemos aparecer

13 De 38 afermaments suscritos por notarios de Valencia durante el quinquenio 1458-1462, solamente uno corresponde a un macip varón a quien el patrono no debía enseñar su profesión, sino a leer y escribir. Los 37 restantes corresponden a niñas que recibirían su correspondiente soldada en metálico al final del periodo contratado (SIXTO, La contratación laboral, p. 229).

14 BRESC, Henri (1990), "École et services sociaux dans les cités et les 'terres' siciliennes (XIIIe-XV siècles)", en Città e servizi sociali nell'Italia dei secoli XII-XV: 12 Convegno di Studi (Pistoia, 9-12 ottobre 1987), Centro Italiano di Studi di Storia e d'Arte, Pistoia, pp. 1-20, y especialmente pp. 12-13.

15 KLAPISH-ZUBER, Christianne (1984), "Le chiavi fiorentine di Barbablú: I'apprendimento della lettura a Firenze nel XV secolo", Quaderni Storici, 57, pp. 765-791. 
desde finales del siglo XIV reclutaban la mayor parte de su clientela entre los medios sociales acomodados.

El sistema escolar de la época no distinguía entre maestros elementales y de segunda enseñanza. Unos y otros se diferenciaban únicamente por su mayor o menor competencia pedagógica. Algunos maestros podían hacerse cargo tanto de la enseñanza elemental como de los programas más avanzados de artes liberales; otros se dedicaban tan solo a enseñar a leer y escribir, como cierto Vicent Conquist, calificado en 1434 como mestre de scolans de legir por un escribano judicial. ${ }^{16}$ Las escuelas mejor dotadas distribuían a los estudiantes en diversos niveles de aprendizaje. Se ha acreditado la existencia de hasta seis clases diferentes en función de los conocimientos latinos, pero eran pocas las escuelas que contaban con las instalaciones necesarias para separarlas de manera efectiva, por lo que las distinciones más próximas se atenuaban hasta quedar reducidas a una división única, la que distinguía entre los estudiantes que habían adquirido ya cierto dominio de la gramática latina y los que aún se enfrentaban a sus rudimentos. ${ }^{17}$ En cualquier caso, algunos autores ya han señalado que la multiplicación de categorías en el aprendizaje gramatical respondía, antes que a un programa pedagógico integral y coherente, a la necesidad de establecer con claridad las obligaciones docentes y los derechos salariales de los maestros. ${ }^{18}$

Al contrario que la enseñanza laboral, que experimentó desde el siglo XIV una creciente regulación por parte de los poderes municipales, la educación literaria fue considerada siempre un asunto privado que correspondía exclusivamente a los padres. No existía normativa pública alguna sobre la escolarización infantil o los términos en que debía llevarse a cabo la contratación de maestros, que quedaban sometidos a la voluntad de las partes. Cabe pensar, incluso, que se trataba de un asunto para el que ni siquiera se recurría al notario, que solamente intervenía cuando los tutores legales de los niños se veían obligados a justificar ante la justicia las cantidades desembolsadas en forma de salarios escolares. De la misma manera que las escuelas de las catedrales y monasterios formaban parte de las estructuras domésticas de las comunidades religiosas, las escuelas laicas urbanas

16 ARV, Justicia de Trescientos Sueldos, 36; 1434, febrero 5.

17 FROVA, Carla (1981), Istruzione e educazione nel Medioevo, Loescher, Turín, pp. 102-103.

18 FROVA, Carla (1992), "Le scuole municipali all'epoca delle università", en WEIJERS, Olga (ed.), Vocabulaire des écoles et des méthodes d'enseignement au Moyen Age, Brepols, Turnhout, pp. 177-190, y especialmente pp. 189-190. 
se adaptaron a la domesticidad burguesa. El maestro no era un "educador público" sino un servidor doméstico especializado que, entre las paredes de la escuela, ejercía como un trasunto del padre, haciendo uso de la potestad que correspondía a éste dentro de la casa familiar. ${ }^{19}$

La idea socialmente difusa de que las condiciones en que se impartía la enseñanza escolar solamente concernía a las partes, es decir, a los maestros y a los propios padres o tutores de los niños, supuso un obstáculo difícil de salvar para quienes propugnaron desde finales del siglo XIV la intervención municipal. Pero tampoco era este el único obstáculo, porque era necesario contar también con la capacidad normativa que la Iglesia se arrogaba en este sector educativo, expresión de una vocación educadora que los decretos promulgados por los concilios de Letrán III y IV, celebrados en 1179 y 1215 respectivamente, habían extendido al conjunto de la sociedad y no únicamente a los clérigos. ${ }^{20} \mathrm{El}$ monopolio eclesiástico de la instrucción literaria era una realidad firmemente enraizada en el desinterés y la incompetencia de los distintos poderes laicos. En el siglo XIII, y en lugares con altas tasas de desarrollo urbano como Flandes o Italia, las cosas habían comenzado a cambiar; ${ }^{21}$ pero no parece que esos nuevos aires llegaran a la Península Ibérica hasta bastante tiempo después. ${ }^{22} \mathrm{El}$ fuero de Jaume I, que aseguraba según algunos autores la completa libertad de enseñanza, constituía en realidad una exención tributaria acorde con los decretos conciliares lateranenses que consideraban simoníaca la venta del conocimiento:

Atorgam que tot clergue o altre hom pusque franchament e sens tot serviï e tribut tener estudi de gramàtica e de totes altres arts e de física e de dret civil e canònich, en tot loch per tota la ciutat. ${ }^{23}$

No parece probable que el monarca pretendiera, a mediados del siglo XIII, sembrar dudas sobre el carácter eminentemente eclesiástico de la educa-

19 MITTERAUER, Michael (1991), I Giovanni in Europa dal Medioevo a oggi, Laterza, Roma-Bari, pp. 173-175 (ed. or. Sozialgeschichte der Jugend, Suhrkamp, Frankfurt am Main, 1986).

20 MANACORDA, Mario A. (1987), Historia de la educación (1). De la Antigüedad al año 1500, Siglo XXI, México, pp. 224-225.

21 PIRENNE, Henri (1929), "La instruction des marchands au Moyen Age", Annales d'Histoire Économique et Sociale, 1, pp. 13-28.

22 GARCÍA, Antonio, "Vocabulario de las escuelas en la Península lbérica", en WEIJERS, Vocabulaire des écoles, pp. 157-176.

23 COLÓN, Germà i GARCÍA, Arcadi (eds.) (1999), Furs de València, VIII, Barcino, Barcelona, p. 140. 
ción literaria, y desde el momento en que no asumía para sí mismo el control de los contenidos de la enseñanza y de la competencia de los maestros, lo dejaba todo en el mismo punto que estaba anteriormente, es decir, en manos de los obispos. Sin duda podían existir maestros que no fueran clérigos, como señalaba expresamente el fuero en cuestión, pero eso no quería decir que por no serlo quedaran al margen del control episcopal, algo que resulta del todo evidente en la documentación eclesiástica, como veremos.

En las décadas que siguieron a la conquista de Valencia, las únicas escuelas de gramática que han dejado algún rastro son las eclesiásticas, y la principal de ellas la que mantenía la catedral desde 1259 al menos. ${ }^{24}$ El primer regente de la escuela capitular de gramática cuyo nombre conocemos fue Ramon Algarra, doctor scholarum, a quien se menciona en un documento de $1308 .{ }^{25}$ La iglesia, que contaba con una difusa red de parroquias y conventos, era la única institución que contaba con los medios humanos y materiales necesarios para asumir un empeño docente que comenzaba por las propias necesidades formativas del clero. Estos medios eran los que, en virtud de las prescripciones conciliares, debían ponerse también a disposición de los laicos. Sin que sepamos desde qué momento, en los márgenes de este sistema eclesiástico comenzaron a actuar algunos clérigos y laicos que enseñaban privadamente tras obtener del obispo la oportuna licentia docendi. El primer maestro laico cuyo nombre conocemos fue cierto Bartomeu Coletes, que contrajo matrimonio en $1336 .{ }^{26}$ Hacia mitad de esta centuria encontramos los nombres de algunos más, en un momento en que los docentes eclesiásticos conocidos ya comienzan a ser numerosos.

La demanda educativa crecía en la sociedad urbana desde el siglo XII, y desde el momento en que había más laicos dispuestos a pagar por la enseñanza, las contradicciones crecían dentro del sistema educativo eclesiástico. La doctrina conciliar respecto al precio de la enseñanza había quedado fijada en los mencionados concilios de Letrán: el conocimiento era un don divino y, en consecuencia, venderlo era un acto simoníaco. El maestro

24 Sanchis Sivera afirma que la asignación "de la escuela de la ciudad" hecha en 1240 por el obispo de Valencia, Ferrer de Pallarés, a favor del maestro Domingo, chantre de la catedral, no supuso la creación de la escuela capitular de gramática, que no aparecería propiamente hasta 1259 por decreto del obispo Andreu Albalat, sino que respondía a la supervisión de las escuelas que se abrieran en la ciudad, SANCHIS SIVERA, José (1936), "La enseñanza en Valencia en la época foral", Boletín de la Academia de la Historia, 108, pp. 147-179 y 661 696, especialmente pp. 153-156.

25 SANCHIS SIVERA, "La enseñanza en Valencia", 108, p. 167.

26 ARV, Protocolos, 2801; not. Bernat Costa, 26 de enero 1336. 
eclesiástico era ante todo un clérigo y sus medios de vida debían ser los propios de los clérigos, es decir, las rentas que reportaban sus cargos y beneficios. El problema estaba en que el incremento de la demanda educativa abría a los docentes la posibilidad de ampliar sus ganancias haciéndose retribuir por sus escolares. El principio canónico de la gratuidad de la enseñanza no resistió durante mucho tiempo el choque con la realidad, y aunque vender el conocimiento siguió siendo considerado pecaminoso, pronto dejó de serlo hacerse pagar por el trabajo que suponía enseñar. El papa Honorio III establecía en 1219 que, "a pesar de cualquier otra costumbre o norma", los obispos debían conceder estipendios especiales a los clérigos dedicados a la enseñanza de la teología que no obtuvieran ingresos suficientes a cuenta de sus beneficios. ${ }^{27}$ Un siglo más tarde, en 1317, el obispo y el cabildo de la catedral de Valencia pagaban sendas subvenciones a los maestros que regentaban la escuela capitular de gramática, por un monto total de 18 libras valencianas anuales. Transcurrida una centuria, en 1398, esta cantidad no había aumentado, pero para entonces los maestros capitulares cobraban colectas a sus estudiantes con absoluta normalidad. Sabemos que este sistema de retribución mixta -subvenciones institucionales y salarios privados- existía desde al menos 1351, y que sus ingresos, en el caso de los clérigos-maestros, podían verse incrementados a cuenta de las correspondientes rentas eclesiásticas. Sin embargo, esta últimas ya no eran imprescindibles: subvenciones y salarios bastaban para hacer del magisterio una ocupación económicamente atractiva, como parece indicar el hecho de que, por esas fechas, el cabildo valenciano comenzó a contratar maestros laicos para dirigir la escuela capitular, lo que suponía un rasgo evidente de profesionalización de la docencia. El primero de esos regentes laicos del que tenemos noticia fue, en 1359, el maestro Pere Figuerola, a quien encontraremos unos años más tarde asesorando a los jurados en asuntos escolares. ${ }^{28}$

En la segunda mitad del siglo XIV las escuelas eclesiásticas valencianas incumplían los preceptos conciliares que sancionaban la gratuidad de la enseñanza y los clérigos dedicados a la docencia literaria actuaban, en lo que tocaba a los aspectos económicos de su profesión, de la misma forma que los maestros laicos, cada vez más numerosos. En condiciones de creciente competencia, la capacidad de control que la autoridad episcopal tenía sobre el sector constituía un instrumento privilegiado a la hora de 
regular la oferta educativa, aunque el tercer concilio de Letrán había establecido claramente las obligaciones de los obispos respecto a la concesión de la licentia docendi: no podían exigir precio alguno por ella ni negarla a quienes estuvieran capacitados para enseñar. ${ }^{29}$ Pero el incremento de la demanda, que impulsaba al alza las retribuciones de los regentes de escuelas eclesiásticas que actuaban con la correspondiente licencia episcopal, facilitaba también el concurso de otros clérigos y laicos que, desprovistos de ella, ponían en cuestión el monopolio que en la práctica pretendían ejercer los primeros. Los conflictos por intrusismo profesional en la enseñanza literaria se desataron primero entre los clérigos, como reflejan algunas intervenciones del obispo de Valencia.

Así, en 1334, el prelado concedió permiso a Pere Soguer, vicario perpetuo de Jérica, para que él mismo o un sustituto suyo utilizara la iglesia o la abadía para instruir a escolares, a pesar de que anteriormente el oficial del propio obispo había hecho idéntica concesión a otro clérigo local. En 1372, el obispo escribía a la iglesia parroquial de Albaida para informar que había facultado al vicario Felip d'Erbach, bachiller en derecho canónico, como regente de las escuelas del lugar, y ordenaba que fuera publicada una admonición pública con pena de excomunión contra cierto Pere Dezquer, beneficiado de esa misma iglesia, y en general contra cualquier otro clérigo o laico que le hiciera la competencia. Al año siguiente, el obispo facultó a Felip d'Erbach para regir las escuelas de gramática de Gandia, amenazando con la excomunión a los clérigos de la villa que tomaran discípulos más allá de uno o dos procedentes de sus propios círculos de familiares y amigos. ${ }^{30}$

\section{La intervención escolástica municipal y la iglesia. Colaboración y CON- FLICTO}

Aunque tenemos constancia de que en 1319 se había producido un primer intento por parte de los jurados de Xàtiva de abrir una escuela en la

29 Pro licentia vero docendi nullus pretium exigat, vel sub obtentu alicuius consuetudinis, ab iis qui docent, aliquid quaerat; nec docere quempiam, petita licentia, qui sit idoneus, interdicat. Qui vero contra hoc venire praesumpserit, a beneficio ecclesiastico fiat alienus. Dignum quidem esse videtur, ut in ecclesia Dei fructum laboris sui non habeat, qui cupiditate animi vendit licentiam docendi (...), MANSI, Giovanni D., ed. (1778), Sacrorum Conciliorum Nova et Amplissima Collectio, vol. 22, Antonio Zatta, Venecia, p. 228 [Documenta Catholica Omnia: http://www.documentacatholicaomnia.eu/04z/z_1692-1769_Mansi_JD_Sacrorum_Conciliorum_Nova_Amplissima_Collectio_Vol_022_LT.pdf.html].

30 (...) nisi unum vel duos proximos vel affines eorum, SANCHIS SIVERA, José (1936), "La enseñanza en Valencia en la época foral", Boletín de la Academia de la Historia, 109, pp. 7-80, especialmente pp. 22 y 31. 
ciudad, ${ }^{31}$ las intervenciones municipales en el terreno de la enseñanza literaria no se generalizaron hasta las décadas centrales del siglo XIV, cuando tuvieron lugar los primeros enfrentamientos con el obispo de Valencia a cuenta del uso que hacía de la licentia docendi para favorecer prácticas monopolísticas manifiestamente contrarias a los decretos conciliares. El caso que mejor conocemos es el de Sagunt, merced a los documentos reunidos por Sanchis Sivera. En 1336 los jurados contrataron un maestro municipal de gramática para quien pidieron protección al prelado valentino contra ciertos maestros, tam clerici quam layci, que consideraban incapacitados para ejercer la docencia. El obispo, haciendo uso de un derecho de control que nadie al parecer cuestionaba, ordenó que dichos maestros fueran examinados por dos médicos de la villa. No parece que el resultado del peritaje favoreciera al municipio, porque dos años después el obispo intervenía de nuevo para apaciguar el conflicto abierto entre dos docentes, uno que ejercía la enseñanza en Sagunt "desde antiguo" y otro recientemente instalado, sin que podamos saber cuál de ellos era el que anteriormente había contratado el consell. La decisión episcopal de permitir que ambos siguieran actuando chocaba abiertamente con el propósito de controlar la competencia que demostraban las autoridades municipales. Sin embargo, en 1345, el obispo pareció avenirse a los deseos de los jurados cuando prohibió enseñar en Sagunt a otros clerici et layci de cuya capacidad docente dudaba. El acuerdo no duró mucho. En 1354 todos los maestros que enseñaban en la villa fueron llamados por el obispo para examinar su aptitud, un hecho que pone en duda la eficacia de la prohibición decretada unos años antes y evidencia que el municipio no había conseguido asegurarse el control de la oferta educativa. El conflicto con la Iglesia se hizo patente en 1358, cuando tras dar licencia a un maestro de gramática para ejercer en Sagunt, el obispo recurrió al argumento de la libertad foral de enseñanza a fin de conjurar la oposición del municipio. ${ }^{32}$ En Valencia, la primera intervención municipal en el sector de la enseñanza literaria no se produjo hasta marzo de 1373. Las motivaciones de la iniciativa se hicieron explícitas en las actas del consell: las precarias condiciones en que ejercían su oficio los maestros de gramática y lógica de la ciudad, y en particular el maestro subvencionado por la catedral, que al parecer ni disponía de locales adecuados, perjudicaban a los escolares y a sus

31 VILLANUEVA, Joaquín Lorenzo (1902), Viaje literario a las iglesias de España, tomo II, Imprenta Real, Madrid, 1804, pp. 97-98.

32 Idem, pp. 20-27. 
padres. La solución adoptada fue adquirir un inmueble para instalar a los maestros en condiciones ventajosas, es decir, mediante alquileres subvencionados. ${ }^{33}$ La compra, que se formalizó el 23 de septiembre de 1373, afectó a varias casas contiguas situadas en la parroquia de Sant Bartomeu, junto a la vieja muralla musulmana, en la calle que actualmente se denomina Mare Vella y que durante buena parte del siglo XV sería conocida como de les escoles de Valldigna, pues estaba próxima a la casa que dicho monasterio tenía en la capital. En 1373 se trasladó allí la escuela capitular de gramática, dirigida entonces por un maestro laico llamado Gil Remírez. ${ }^{34}$

No parece que al principio la intención del consell fuera poner en cuestión el control eclesiástico de la enseñanza literaria; el hecho de que se preocupara por mejorar las condiciones de la escuela del cabildo habla más bien de un episodio de colaboración entre ambas instituciones. Pero en última instancia la intervención se justificaba por la poca atención que el obispo y el cabildo prestaban a su propia escuela, ya que las subvenciones que asignaban al maestro no permitían acceder a instalaciones decentes. De ahí a poner en duda la capacidad de la Iglesia para controlar la enseñanza literaria había un paso, y parece que el desembolso realizado para comprar los nuevos locales de Sant Bartomeu animó a los jurados a cruzar esa línea. Si en un primer momento pretendían solamente reubicar la escuela de la catedral, a finales del mes de septiembre de 1373 estaban buscando un maestro de reconocido prestigio a quien ofrecer la dirección de la que ya sin rodeos denominaban escola major de la ciudad. Era la única forma, decían los jurados, de acabar con las disputas desatadas entre los maestros locales por hacerse con las nuevas instalaciones municipales. En este punto se esfumaba la preeminencia que habían reconocido hasta entonces al maestro capitular, que ya no era sino uno más de los que andaban a la greña y estaba tan poco cualificado para la docencia como el resto. ${ }^{35}$

Ahora el municipio exponía abiertamente su intención de acabar con el control de la Iglesia sobre el sector educativo para sustituirlo por el suyo propio. El obispo y el cabildo reaccionaron ante el ataque alegando las disposiciones conciliares que les capacitaban para poner orden en el sistema escolar; y tal vez porque no tenían demasiada fe en la contundencia del argumento, recurrieron también a la libertad de enseñanza recogida en

33 VIVES LIERN, Vicente (1902), Las casas de los estudios en Valencia. Informe acerca del sitio en que éstas se hallaban emplazadas, Ayuntamiento, Valencia, pp. 16-17.

34 VIVES LIERN, Las casas de los estudios en Valencia, pp. 35-40.

35 SANCHIS SIVERA, "La enseñanza en Valencia", 109, pp. 40-41. 
los fueros del reino. A su vez, los jurados acusaron al obispo de sustentar el monopolio educativo de Gil Remírez, persiguiendo con vetos y excomuniones a sus competidores, ya que el docente había obtenido su protección mediante sobornos. En septiembre de 1374, y en medio de acusaciones cruzadas de contrafuero y simonía, el obispo de Valencia ordenó encarcelar a Pere Costa, el maestro contratado poco antes por el consell para abrir una escuela que compartiera los locales de Sant Bartomeu con el maestro del cabildo. El prelado alegaba la condición de tonsurado de Costa y se negaba a dar mayores explicaciones. La respuesta de los jurados, que no estaban dispuestos a quedarse atrás en la escalada, fue recluir en la presó comuna a Gil Remírez, aduciendo que se había retrasado en el pago del alquiler. Finalmente, tras diversas reuniones y embajadas, ambos contendientes acordaron intercambiar rehenes y los maestros fueron excarcelados. A continuación, el consell hizo publicar un bando que advertía de que el monopolio escolar era contrario a los fueros, acusando implícitamente al obispo y el cabildo de haber provocado el conflicto. ${ }^{36}$

La primera tentativa intervencionista del municipio valenciano terminó sin un vencedor claro. Los maestros Gil Remírez y Pere Costa convivieron a partir de entonces en las escuelas de Valldigna, no sin padecer serias angustias financieras a cuenta de la continuidad de las subvenciones que recibían de la catedral y el consell. Por su parte, y aunque fracasaron en la pretensión de poner la enseñanza literaria bajo su propia tutela, los jurados habían conseguido poner fin al control eclesiástico. Entre finales del siglo XIV y princios del XV se consolidó dentro del gobierno ciudadano un grupo de opinión que propugnaba completar la tarea emprendida en 1373. El activista más destacado fue el maestro en artes y medicina Pere Figuerola, antiguo regente de la escuela capitular de gramática que, a raíz del conflicto con el obispo, se había convertido en el principal asesor de los jurados en materia escolástica. En sus intentos de redactar y poner en práctica sucesivas ordenanzas escolares, Figuerola se rodeó de colaboradores tan eminentes como el teólogo Francesc Eiximenis, quien en 1399 encabezó una comisión municipal encargada de hacer un reglamento para centralizar las escuelas de la ciudad. Entre 1389 y 1405 el consell aprobó sucesivamente tres ordenamientos escolares, además de otras disposiciones cuya finalidad era asegurar la eficacia de tales normativas. Pero todos estos esfuerzos, incluyendo los del franciscano Eiximenis, cayeron en saco roto, lastrados por la opinión contraria de quienes, dentro del propio

36 TEIXIDOR, José (1976), Estudios de Valencia (Historia de la Universidad hasta 1616), ed. de Laureano Robles, Universidad de Valencia, Valencia, p. 99. 
municipio, consideraban insalvable el precepto de la libertad foral de enseñanza. De hecho, ninguna de aquellas tres ordenanzas llegó siquiera a registrarse por extenso en los libros de actas. ${ }^{37}$

La cuestión de la unificación de las escuelas era un aspecto central de la polémica educativa. Los partidarios de la intervención la consideraban indispensable para asegurar la rentabilidad de las escuelas subvencionadas por la ciudad, que debían ocupar locales amplios y bien acondicionados y, en consecuencia, soportar importantes gastos. Para conseguir atraer maestros con la formación y el prestigio adecuados no bastaba con ofrecerles subsidios, normalmente en forma de alquileres a precio político, sino también asegurarles unas nutridas clientelas que reportaran abundantes colectas. El problema era menos grave para la Iglesia, cuyos maestros contaban con ingresos complementarios procedentes de las rentas beneficiales. Aunque los obispos intentaron, como ya hemos visto, controlar la oferta educativa mediante la concesión de la licencia docendi o fulminando penas espirituales sobre los maestros incontrolados, no parece que llegaran a considerar la posibilidad de reunir todas las escuelas eclesiásticas en un único centro, necesariamente el de la catedral, ya que la medida hubiera supuesto el cierre de las escuelas parroquiales que pudieran existir en aquella época. Pese a las acusaciones de los jurados, en el conflicto de 1374 el obispo no pretendía tanto imponer un verdadero monopolio escolar como impedir que la intervención del consell pusiera en peligro el control eclesiástico sobre la enseñanza literaria. El resultado del enfrentamiento no fue favorable a la Iglesia, obligada desde entonces a compartir sus competencias con el municipio, pero tampoco éste consiguió imponer otra cosa que la existencia de un centro subvencionado propio. Los posteriores intentos de unificación escolástica no tuvieron más éxito, y no tanto por la oposición de la Iglesia como por la que surgía dentro del propio gobierno municipal, a la que se sumaban muchos maestros independientes que temían verse expulsados del ejercicio de la profesión docente. En el mes de agosto de 1400 los jurados llegaron a organizar un debate público en el que participaron varios maestros en artes y gramática, partidarios unos de que se reunieran en un solo lugar todas las escuelas de la ciudad y otros de la dispersión existente. El resultado era importante porque se trataba de aprobar los estatutos escolares compuestos por la comisión de Francesc Eiximenis. Al final no pudo sino constatarse la disparidad de opiniones, de manera que sin un acuerdo que permitiera alterar el marco legal vigente, es decir, la libertad

37 CRUSELLES, José Ma (2012-2014), "Francesc Eiximenis y la política escolar de la ciudad de Valencia (1389-1412)", Anales de la Universidad de Alicante: Historia Medieval, 18, pp. $271-301$. 
foral de enseñanza, los estatutos de Eiximenis acabaron guardados en un cajón. Tampoco tuvieron mejor fortuna posteriores tentativas de implantar un examen municipal para maestros de gramática, en 1403, o de redactar un nuevo reglamento escolar en $1405 .^{38}$

Luego, a partir de 1407, las cosas comenzaron a cambiar y el resultado fue una intervención mucho más decidida que la de 1373. El municipio emprendió los trámites para adquirir otro inmueble, esta vez de mayores dimensiones, situado en la parroquia de Sant Llorenç, en la plaza del mismo nombre, que en 1411 fue ocupado por maestros y escolares. El año anterior se había acometido la tarea de redactar nuevos estatutos, los cuartos desde 1389. El ambicioso proyecto contemplaba reunir las escuelas del cabildo y el municipio en un único centro que gozaría del monopolio de la instrucción literaria en la ciudad. Para ello, el consell sometió el reglamento a la aprobación del obispo, y se creó una sociedad de maestros regentes en la que se integraron tanto los del cabildo, Vicent Soler y Joan d'Ordós, como otro designado por el municipio, Martí de Sohiça. Sin embargo, las resistencias persistían. En 1412, dos de los jurados declararon expresamente su oposición a los nuevos estatutos escolares porque vulneraban los fueros, y al mismo tiempo, las disensiones surgidas entre los maestros tampoco contribuían al éxito final de la empresa. La ruptura de la sociedad rectora de las escuelas de Sant Llorenç llevó a un nuevo enfrentamiento entre la catedral, que reclamaba el derecho a seguir manteniendo su propio centro, y el municipio, que defendía ahora posiciones abiertamente monopolísticas. Cuando en 1416 los jurados intentaron cerrar la escuela que el maestro capitular Joan d'Ordós había abierto en la parroquia de Sant Nicolau, aquel recurrió al tribunal de la Gobernación alegando la libertad foral de enseñanza y consiguió una sentencia favorable que puso fin, durante casi un siglo, a ulteriores pretensiones centralizadoras por parte del municipio. Todo intento de control de la competencia desapareció y comenzaron a proliferar los estudiantes de artes que abandonaban su trabajo como preceptores privados o maestros auxiliares (cambrers) para abrir sus propias escuelas en cualquier parte de la ciudad. ${ }^{39}$

38 SANCHIS SIVERA, "La enseñanza en Valencia", 109, pp. 43-45; VIVES LIERN, Las casas de los estudios en Valencia, pp. 28-29.

39 CRUSELLES, Escuela y sociedad, pp. 56-63. 


\section{El SISTEMA ESCOLAR VALENCIANO DEL SIGLO XV: LAS SOCIEDADES DE MAESTROS}

Pero el fracaso no acalló a quienes dentro del consell estaban decididos a seguir interviniendo en el sector escolástico, aunque redujo sus pretensiones a una dimensión bastante más modesta que incluía la definitiva renuncia a concentrar las escuelas. El procedimiento elegido era conocido: ofrecer locales escolares a precio subvencionado. Fue necesario vender el gran inmueble de la plaza de Sant Llorenç -reconvertido a finales del siglo XV en palacio de la familia Borja y sede en la actualidad de las Cortes Valencianas-y trasladar la escuela municipal a otro de capacidad más reducida a fin de abaratar costos. La solución finalmente adoptada fue la de volver a comprar las escuelas de Valldigna, cuyo dominio útil había vendido el municipio tras el conflicto de 1374, y que en 1417 poseían los herederos del maestro Gil Remírez, fallecido en 1407. La operación, que incluía la compra de otro inmueble colindante que según Vives Liern correspondía a la antigua escuela del maestro Pere Costa, supuso para las arcas municipales un desembolso de 425 libras, además de otras 7'5 libras que había que pagar anualmente por una pensión censal que Remírez había cargado sobre la casa y que la ciudad se subrogó en el momento de la compra. ${ }^{40}$

En 1419 el consell instaló en las escuelas de Valldigna una sociedad formada por tres maestros: Bartomeu Morell, Pere Ferrando y Joan Esquerdo. El primero de ellos había trabajado en 1413 como subalterno de Martí de Sohiça en la escuela de Sant Llorenç, para luego abrir junto con sus nuevos socios una escuela independiente que se encontraba activa en 1415 en la parroquia de Sant Nicolau. ${ }^{41}$ El salto a la nueva escuela municipal era importante, tanto en términos de prestigio profesional como puramente económicos. Los maestros debían entregar al consell una entrada de 200 libras y pagar anualmente las 7 ' 5 libras de la pensión censal, comprometiéndose a no utilizar el inmueble para otros fines que los estrictamente escolares. Cuando cesaran en su actividad, el municipio recuperaría la casa previa devolución de las 200 libras de la entrada, que en realidad constituían una fianza. ${ }^{42}$ Así, el precio anual del alquiler quedaba reducido a siete libras y media, cantidad muy inferior a las treinta libras que Morell y Ferrando pagaban en 1415 por la casa donde tenían entonces su escuela, lo que

40 VIVES LIERN, Las casas de los estudios en Valencia, pp. 64-69.

41 ARV, Protocolos, 2414; not. Vicent Saera, 5 de julio 1413; ibidem, 2416; not. Vicent Saera, 20 de agosto 1415.

42 SANCHIS SIVERA, "La enseñanza en Valencia", 109, pp. 56-57. 
da cuenta del alcance que tuvo la política de subvenciones del consell y los jurados. De hecho nunca, a lo largo de toda la centuria, tuvieron problemas para encontrar docentes capacitados y dispuestos a hacerse cargo del centro.

No podemos afirmar que las escuelas de Valldigna albergaran una escuela pública municipal, puesto que la enseñanza no era gratuita. Los maestros vivían de las colectas que pagaban sus estudiantes, de manera que eran estos y sus familias quienes corrían con los gastos de la educación; algo que estaba bien visto por muchos ciudadanos que creían firmemente que aquel era un asunto privado y que no estaban dispuestos a que se destinaran fondos públicos a un servicio cuyos costos debían asumir en exclusiva los interesados. Pero al mismo tiempo, el sistema de alquileres subvencionados aseguraba una oferta educativa estable y a precios razonables, como deseaban muchas familias de ciudadanos acomodados que constituían el principal apoyo del sistema político ciudadano. Una escuela gratuita habría podido facilitar el acceso a la enseñanza literaria de los artesanos modestos, pequeños comerciantes y jornaleros, pero con unos costos que la oligarquía de rentistas, mercaderes y funcionarios que dominaba el gobierno municipal no estaba dispuesta a asumir. Como en otros lugares de Europa, las subvenciones escolares hacían posible que las familias de la clase dirigente encontraran maestros competentes para sus hijos sin necesidad de hacer desembolsos disparatados, pero el sistema escolar como tal seguía fuera del alcance del común de la población, que no podía asumir los costos. ${ }^{43}$

Bartomeu Morell estuvo al frente de las escuelas de Valldigna hasta 1429, fecha en que las traspasó a un nuevo regente, Joan de Miravet, que en aquella fecha encabezaba una sociedad de la que formaban parte otros dos maestros: Alegre de Monesma y Bartomeu Gil. Miravet, originario de Alcoi, ejercía la enseñanza en Valencia desde antes de 1424, fecha en la que tenía como socios a los maestros Joan Domingo y Gabriel Moragues. Este último pasó posteriormente a integrarse en las escuelas de Valldigna como socio de Bartomeu Morell, aunque ya había fallecido cuando en abril de 1429 se produjo el mencionado traspaso, de manera que fueron sus herederos quienes recibieron la parte que le correspondía de las 200 libras que Miravet y sus socios entregaron a los maestros salientes en concepto de precio por la cesión de los locales.

La transición entre ambas sociedades de maestros, la primera de las que tuvieron lugar en las escuelas municipales a lo largo del siglo XV, se produ- 
jo sin particulares problemas económicos ni jurídicos, algo destacable en un sector que hasta entonces había resultado particularmente conflictivo. El éxito de la operación tenía mucho que ver con la modestia misma que caracterizaba la política educativa municipal, consecuencia evidente de sus anteriores fracasos. El consell había renunciado a intervenir en cualquier aspecto relativo a la ordenación de la enseñanza que trascendiera la gestión de los locales escolares. No existía una normativa municipal que impusiera criterios de idoneidad a los docentes, estableciera los contenidos de la docencia o determinara la jerarquía interna de la empresa escolar. Todos estos asuntos se resolvían mediante acuerdos privados que los propios maestros formalizaban en las oficinas notariales, tomando como modelo los contratos de sociedad mercantil habituales en la época. Las autoridades municipales se reservaban solamente la facultad de arbitrar en las disputas entre socios, y la de ordenar el traspaso del inmueble de unos maestros a otros para asegurar el uso escolar. ${ }^{44}$

No sabemos en qué circunstancias se produjo el relevo de Joan de Miravet al frente de las escuelas municipales, aunque suponemos que tuvo lugar entre 1456 y 1459 . En la primera de esas fechas, transcurridos treinta años desde que el maestro se hiciera cargo del centro, éste era identificado en las actas del consell como les scoles appel/lades de mestre Miravet. En la segunda fecha, cuatro años más tarde, ya había recuperado su antigua denominación de escuelas de Valldigna y los jurados reconocían al maestro Pere Gil, ciudadano de Valencia, como propietario de la mitad del inmueble. ${ }^{45}$ Ignoramos quienes eran los socios de Pere Gil y hasta qué momento permaneció al frente del centro, aunque por informaciones indirectas sabemos que en 1489 seguía ejerciendo como magister scolarum. ${ }^{46}$ En 1490 las escuelas de Valldigna pertenecían a cierto Pere Abat, originario de Alcoi, cuyos herederos las vendieron al año siguiente a una sociedad de maestros constituida por Melcior Mont y Jaume Esteve. ${ }^{47}$ Podemos pensar que ambos dirigieron el centro durante la siguiente década, aunque solamente contamos con alguna noticia relativa a la actividad de Jaume Esteve, que en 1493 compraba sesenta ejemplares de un tratado de lógica con la probable intención de distribuirlos entre sus estudiantes. ${ }^{48} \mathrm{El}$ hecho de que Esteve ocupara a partir de 1499 la cátedra de lógica del recién creado Estudio General de Valencia, ${ }^{49}$ viene a confirmar que hasta entonces había

44 CRUSELLES, José $M^{a}$ (2008), "El maestro Joan de Miravet y la escuela municipal de Valencia en la primera mitad del siglo XV", Saitabi, 58, pp. 93-108, esp. pp. 99-101.

45 AMV, Manuals de Consells, A-36, ff. 132v y 197.

46 ACCV, Protocolos, 9956; not. Pere Avellà, 9 de julio 1489.

47 ARV, Protocolos, 1686; not. Lluís Navarro, 21 de agosto 1491. 
sido regente de las escuelas de Valldigna y que en esa fecha se incorporó junto con sus estudiantes a la Universidad:

En lo mes de agost del dit any [1499] foren tots los estudiants de les Escoles de Valldigna, de mestre Tristany y de la de Vallada, al Estudi General, que hui és per orde dels Jurats, los quals havien comprat la casa dels hereus de $M^{n}$ Serrano, per fer dit Estudi General. ${ }^{50}$

Aunque de manera fragmentaria, podemos también reconstruir el devenir de las otras dos escuelas mencionadas en el Llibre de Memòries como contribuyentes netas de la Universidad. La llamada escuela de la Avallada tuvo su origen en la ruptura de la sociedad de maestros constituida en 1412 para dirigir la escuela de Sant Llorenç, de la que había formado parte el presbítero y maestro de gramática Joan d'Ordós. Este, que en el momento de la crisis era el maestro subvencionado por la catedral, se trasladó a unos nuevos locales situados en la parroquia de Sant Nicolau, en la calle de la Avallada de Batiste Burgarini, actualmente llamada Burguerins, muy cercana a la iglesia de Sant Nicolau. ${ }^{51}$ Esta fue la escuela que los jurados intentaron cerrar en 1416. El recurso de Joan d'Ordós a la corte de la Gobernación obligó al municipio a rediseñar su política educativa, lo que supuso el cierre definitivo de la escuela de Sant Llorenç y la reapertura de las escuelas de Valldigna. Por su parte, Ordós permaneció durante el resto de su vida al frente de la escuela de la Avallada, que consolidó su prestigio durante ese largo periodo de estabilidad.

En 1454, tras la muerte de Joan d'Ordós, el cabildo designó al también presbítero Guillem Saura para regentar la escuela. En 1483 la Almoina de la catedral, a cuya propiedad había pasado el inmueble, alquiló la escue-

48 El vendedor era el librero e impresor Miquel Albert, y en el contrato de compraventa se especificaba que Jaume Esteve era maestro de las escuelas de Valldigna, SERRANO MORALES, José Enrique (1899), Reseña histórica en forma de diccionario de las imprentas que han existido en Valencia desde la introducción del arte tipográfico en España hasta el año 1868, Imp. de F. Domenech, Valencia, p. 4.

49 FELIPO, Amparo (1993), La Universidad de Valencia durante el siglo XVI (1499-161 1), Universidad de Valencia, Valencia, pp. 110-111.

50 CARRERES, Salvador (ed.) (1935), Libre de Memóries de diversos sucesos e fets memorables e de coses senyalades de la ciutat e regne de Valencia. 1308-1644, vol. II, Acción Bibliográfica Valenciana, Valencia, pp. 714-715.

51 CARBONERES, Manuel (1873), Nomenclátor de las puertas, calles y plazas de Valencia, Imp. del Avisador Valenciano, Valencia, p. 38. 
la al maestro Bernat Vilanova, que dos años más tarde arrendó una casa contigua para ampliar los locales. En 1499 el cabildo seguía interviniendo en los asuntos de la escuela de la Avallada, aunque en esa misma fecha el centro se integró en la Universidad. ${ }^{52} \mathrm{Al}$ igual que Jaume Esteve, regente de las escuelas de Valldigna, Bernat Vilanova, alias mestre Navarro, se integró en el cuerpo docente del Estudio General, donde desempeñó desde el año 1500 la cátedra de filosofía moral. ${ }^{53}$ No podemos asegurar que Vilanova hubiera seguido dirigiendo hasta aquel mismo momento las escuelas capitulares, pero sabemos con certeza que a partir de 1489 se convirtió en el propietario de la tercera escuela mencionada en el Llibre de Memòries, la que había pertenecido a Antoni Tristany, un maestro de origen judeoconverso muerto en agosto de 1488 en las cárceles de la Inquisición, como resultado presumiblemente de las torturas que allí le fueron infligidas.

Hijo de una familia de artesanos de posición social mediocre, Antoni Tristany ya debía ser un maestro prestigioso y acomodado en 1478, cuando sus padres le hicieron donación de una casa situada en la parroquia de Sant Esteve, cercana a la calle del Vall, actualmente Comedias, que él unió a otra contigua que había adquirido previamente para constituir su propia casa familiar. Sin embargo, su escuela se encontraba en la parroquia de Sant Martí, en un vico sive adzuquat vulgariter dicto d'En Sandalines que no hemos podido situar en el callejero actual. Condenado post mortem como hereje, todos sus bienes fueron confiscados por el Santo Oficio, lo que dio al traste con el proyecto familiar que habría hecho de Pere Tristany el sucesor de su padre al frente de la escuela. Esta fue vendida por la Inquisición al maestro Bernat Vilanova, que había ejercido y tal vez seguía ejerciendo aún como maestro de la escuela capitular. Aunque una tradición historiográfica valenciana señalaba a Tristany como el primer maestro del joven Joan Lluís Vives, ahora sabemos que cuando éste nació, en 1493, el docente llevaba muerto más de un lustro. ${ }^{54}$

\section{LOS ESTUDIOS SUPERIORES Y LA UNIVERSIDAD}

La fundación de la Universidad supuso la victoria final de quienes dentro del consell habían abogado por la regulación escolar y no se conformaban con una moderada política de subvenciones. Sus voces volvieron a dejarse oír con fuerza a partir de 1490, clamando contra el desorden endémico

52 SANCHIS SIVERA, "La enseñanza en Valencia", 108, pp. 670 y 675-676.

53 GALLEGO, Jordán (1980), "La facultad de artes de la Universidad de Valencia desde 1500 hasta 1525", Escritos del Vedat, 10, pp. 215-258, especialmente p. 221.

54 CRUSELLES, José Ma (1995), "El maestro Antoni Tristany y la supuesta primera escuela de Joan Lluís Vives", Estudis. Revista de Historia Moderna, 21, pp. 7-22. 
que en su opinión sufrían las escuelas y los perjuicios que comportaba semejante abandono. El resultado fue un proyecto similar al de la extinta escuela de Sant Llorenç aunque más ambicioso incluso, porque no solo pretendía centralizar la instrucción literaria y asegurar locales escolares adecuados, sino que integraba también los estudios superiores de derecho, teología, filosofía y cirugía, realojando para ello tanto las lecturas públicas que el municipio había mantenido en las décadas anteriores, como las enseñanzas sostenidas por la catedral y los conventos mendicantes.

Desde el siglo XIV, el obispo y el cabildo catedral habían patrocinado, además de la escuela de gramática, otros tres institutos educativos destinados a asegurar la correcta formación del clero. La cátedra de teología se creó en 1345 y fue regentada por los dominicos hasta 1443, las primeras noticias sobre las escuelas de canto datan de 1351 y, por último, la escuela de derecho canónico fue inaugurada en 1376 bajo la dirección de Bonifaci Ferrer. ${ }^{55}$ Sabemos que estas enseñanzas atrajeron pronto el interés de los laicos, muchos de los cuales veían en el desempeño de cargos eclesiásticos una opción profesional en auge. El fuerte incremento del cuerpo clerical que venía experimentando la Cristiandad latina desde el siglo XII llevó en la centuria siguiente hasta la universidad a muchos estudiantes que procedían de los grupos dirigentes y acomodados de la sociedad, aquellos que tenían medios para sufragar prolongadas estancias en ciudades lejanas y países extranjeros. Estos graduados universitarios ocuparon pronto los cargos altos y medio-altos de la jerarquía clerical, que eran los más apetecibles y escasos. Pero por debajo de ellos quedaban muchos otros puestos que, aun resultando menos destacados y lucrativos, ejercían un atractivo poderoso sobre gentes de condición más modesta, como notarios, mercaderes, tenderos e incluso algunos miembros del artesanado urbano. Muchos de ellos no disponían de medios para dar a sus hijos formación literaria en las universidades, de manera que recurrían a los centros educativos locales, las pequeñas escuelas urbanas, eclesiásticas o municipales, y a maestros particulares. ${ }^{56}$

Sin embargo, el interés de los grupos medios urbanos por la enseñanza superior trascendía el ámbito estricto de las estrategias ocupacionales para adentrarse en el de las identidades culturales, y esto atrajo necesariamente la atención de quienes gobernaban la ciudad. En 1401, una carta remitida

55 SANCHIS SIVERA, "La enseñanza en Valencia", 108, pp. 172-175.

56 Valga como ejemplo el contrato suscrito en 1426 entre Jeroni Manyes y el maestro Gabriel Moragues, quien debería enseñarle gramática y lógica durante dos años, de manera que, poniendo el primero el esfuerzo necesario, pudiera adquirir la competencia necesaria para convertirse en notario o en capellán (ARV, Protocolos, 790; not. Martí Doto; 10 de enero 1426). 
por los jurados de Valencia al papa Benedicto XIII describía el abigarrado alumnado que seguía las lecciones que fray Pere Canals impartía en la cátedra de teología de la sede valentina: doctores, bachilleres, canónigos, médicos, notarios, presbíteros et alii diversorum statuum. ${ }^{57}$ Hacia mediados del siglo XV el municipio estaba dispuesto a atender una demanda que, en general, requería de actuaciones menos controvertidas que la centralización de las escuelas de gramática. La creación de lecturas públicas de poesía, ética, teología y cirugía permitía atraer a la ciudad docentes cuya fama beneficiaba el prestigio de sus gobernantes. Ciertamente, estas iniciativas carecían del respaldo de una verdadera política de instrucción pública, por lo que su existencia fue a menudo efímera y siempre estuvo cuajada de interrupciones y colapsos. En 1461 se creó una lectura de retórica y poesía que desapareció en 1469, volviendo a resurgir en 1498 con el tiempo justo para integrarse, un año más tarde, en el Estudio General. Otras lecturas patrocinadas por el municipio tuvieron una existencia más breve si cabe. La de ética se impartió entre 1465 y 1467, y la de teología entre 1482 y 1484 . Ninguna de las dos sobrevivió el tiempo necesario para pasar a formar parte de la Universidad. La lectura de cirugía constituye la única excepción. Creada en 1462 a la sombre del Colegio de cirujanos, adquirió un papel destacado en los mecanismos de acceso a la profesión, lo que aseguró su continuidad el resto de la centuria. ${ }^{58}$

La fundación de la Universidad en los últimos años del siglo XV fue el resultado más feliz de la reactivación del intervencionismo escolástico municipal. No sabemos si por entonces seguían existiendo defensores de la libertad foral de enseñanza, ni si tuvieron capacidad para oponerse al proyecto, aunque el nuevo Estudio General contaba con apoyos muy encumbrados, como el papa Alejandro VI y el rey Fernando, lo que facilitó sin duda que el viejo fuero de Jaume I pudiera ser arrumbado. No parece, sin embargo, que la nueva institución consiguiera frenar la emigración escolástica que desde hacía más de dos siglos llevaba a los estudiantes valencianos hasta las universidades europeas; sobre todo en el ámbito de los estudios de derecho civil, sin duda los que tenían mayor demanda entre los grupos medios y altos de la sociedad urbana. De los 107 graduados en esta facultad entre 1526 y 1561 , tan solo siete eran valencianos. Estos

57 TEIXIDOR, Estudios de Valencia, p. 95. Conocemos a algunos de los estudiantes que frecuentaron a lo largo del siglo XV las instituciones de enseñanza superior existentes en la ciudad de Valencia, entre los que se contaban tanto hijos de caballeros como de notarios, mercaderes y artesanos, Autocita.

58 DE LA TORRE, Antonio (1924-1925), "Precedentes de la Universidad de Valencia", Anales de la Universidad de Valencia, 5, pp. 175-301, especialmente pp. 246-266. 
eran mayoritarios en las facultades de artes liberales y teología, es decir, en aquellos estudios que existían previamente en Valencia y habían causado un número menor de desplazamientos. También constituían una parte importante de los estudiantes de medicina. Pero los graduados en derecho eran sobre todo castellanos, que también constituían la mayoría en la facultad de medicina, aunque solo la cuarta parte en teología. ${ }^{59}$ Valencia, que desde finales del siglo XIV se había convertido en un poderoso mercado portuario que extendía su influencia a las regiones limítrofes de Castilla y Aragón, también atrajo a partir del siglo XVI a muchos estudiantes de estos países que no podían afrontar el desplazamiento a otros centros universitarios más alejados. Por último, y aunque carecemos de estudios pormenorizados, podemos pensar que el Estudio General reordenó eficazmente la enseñanza de la gramática y las artes liberales, acabando con la dispersión y la precariedad del sistema escolar anterior; y que en consecuencia favoreció la práctica de estrategias educativas entre los grupos medios urbanos. El alcance de tales beneficios queda, sin embargo, por determinar.

\section{Conclusiones}

Es posible documentar contactos entre el aprendizaje laboral y la enseñanza de las letras en la documentación valenciana de los últimos siglos medievales, pero el sistema escolástico se situaba, en su conjunto, al margen del mundo del trabajo manual. No parece siquiera que, al contrario de lo que ocurría en lugares como Italia, los grupos mercantiles hicieran un uso significativo de él para transmitir conocimientos técnicos. Sí sabemos que tanto los mercaderes como otros grupos profesionales de notarios, juristas y médicos, recurrieron a la escuela como mecanismo de acceso a los estudios universitarios, que hasta los últimos años del siglo XV habían de realizarse necesariamente fuera del país, y también -aunque carecemos en este punto de estudios más pormenorizados-para dirigir a sus hijos hacia la carrera eclesiástica, que ocupaba un lugar importante en las estrategias de reproducción social de los grupos medios urbanos, incluyendo los segmentos más acomodados del artesanado.

El progresivo crecimiento de la demanda escolar por parte de los laicos, que puede observarse con claridad desde mediados del siglo XIV, forzó importantes trasformaciones en la organización escolar de la lglesia, la única que existía en aquel momento. El principio de gratuidad de la ense- 
ñanza, un pilar básico de la ideología educativa conciliar, se vio forzado hasta desaparecer en la práctica. El control de la autoridad episcopal sobre los clérigos que ejercían la docencia hubo de enfrentarse a crecientes obstáculos, mayores si cabe cuando comenzaron a proliferar también maestros laicos que, ajenos a la jurisdicción eclesiástica, desempeñaban sin embargo una función tradicionalmente sometida a ella, como era la enseñanza literaria. Pero el principal efecto del incremento de la demanda educativa, y el que peores consecuencias tuvo para el mantenimiento del monopolio que el obispo y la catedral habían mantenido sobre el sector desde los tiempos de Jaume I, fue la irrupción de los municipios. En Valencia hemos podido seguir con cierto detalle, desde 1373, las relaciones trabadas entre el cabildo y el consell en torno a esta cuestión. Sin duda, los episodios que más llaman la atención son los conflictos, y se produjeron dos particularmente significativos en 1374 y 1416 . El primero de ellos, un pulso jurisdiccional que los maestros Pere Costa y Gil Remírez sufrieron en sus propias carnes, supuso el final del monopolio eclesiástico y la aparición de la política de subvenciones públicas que dio origen a las llamadas Escoles de Valldigna. El segundo, protagonizado por el maestro Joan d'Ordós, terminó con cualquier intento por parte de las autoridades municipales de trascender dicha política de subvenciones e hizo de la desregulación la principal característica del sector durante todo el siglo XV. Es necesario, sin embargo, prestar más atención a los episodios de colaboración, pues los conflictos no parecen ser sino el resultado del fracaso de aquellos. Así ocurrió con los dos enfrentamientos mencionados. En 1373, la primera intervención del consell en la ordenación escolar tenía como finalidad explícita mejorar las condiciones de la escuela capitular. En 1412, la inauguración de la escuela de Sant Llorenç fue el resultado de la cooperación entre el municipio y la catedral, una breve experiencia que supuso un claro precedente del estado de ánimo que impulsó, casi cien años más tarde, la fundación de la Universidad de Valencia.

Podemos reconstruir parcialmente el devenir de las escuelas urbanas durante el siglo XV gracias sobre todo a la documentación notarial. Los acuerdos entre maestros para formar sociedades escolares que abrían escuelas libres o arrendaban los locales escolares facilitados por el municipio o la catedral, se escrituraban en las mismas notarías y siguiendo las mismas pautas formales que cualesquiera otras sociedades mercantiles del momento. Sabemos, por estos medios, que a lo largo de la centuria existieron en Valencia dos centros escolares que podemos llamar principales por los medios financieros con que contaban y lo nutrido de sus clientelas: las escuelas de Valldigna, reorganizadas por el municipio hacia 1419, y la escuela de la Avallada, que alojó a los maestros subvencionados por el obispo y la catedral desde algún momento un poco posterior a 1412. Las dos parecen 
haber mantenido niveles aceptables de prestigio a lo largo de todo el periodo, resultando piezas claves en la constitución de la facultad de artes de la Universidad, en la que se integraron en 1499. No fueron, sin embargo las únicas escuelas que existieron durante el siglo XV. Algunos maestros aparecen fugazmente en la documentación y de muchos de ellos apenas sabemos algo más que sus nombres. Ignoramos qué entidad pudieron tener sus escuelas; ni siquiera si realmente las tenían o se limitaban a ofrecer servicios a domicilio, particularmente los que eran calificados como maestros de primeras letras. Existían, desde luego, preceptores privados que en la práctica tenían la condición de servidores domésticos de las casas acomodadas; pero también maestros libres cuyas instalaciones, clientela y reputación alcanzaron dimensiones similares a las de quienes enseñaban en los centros subvencionados por los poderes públicos. El mejor conocido es Antoni Tristany, a quien los biógrafos de Joan Lluís Vives identificaban como su primer maestro, pero que ya había muerto en la cárcel de la Inquisición años antes de que el humanista viniera al mundo. Prueba de la fama que llegó a alcanzar, acrecentada sin duda por las dramáticas circunstancias que rodearon su muerte, es que la escuela que fundó y regentó todavía era conocida por su nombre, escola de mestre Tristany, cuando sus estudiantes fueron incorporados a la Universidad junto con los procedentes de las escuelas del municipio y la catedral.

Conocemos bien los entresijos institucionales que condujeron a la fundación de la Universidad de Valencia. Se ha escrito sobre su financiación por parte del consell y la colaboración del segundo papa Borja, Alejandro $\mathrm{VI}$, en su nacimiento. Para los historiadores representa un logro cultural lo bastante evidente como para no indagar mucho más en las causas y circunstancias que hicieron renunciar a una política de intervencionismo atemperado que había dado buenos resultados, aunque sin duda modestos, a lo largo de toda la centuria. Cabe pensar que la demanda de estudios avanzados hubiera crecido rápidamente en la ciudad desde mediados del siglo XV, como parece indicar el interés del municipio por financiar lecturas públicas de poesía, teología o cirugía. No cabe duda de que la Universidad reorganizó tales esfuerzos y les dio una mayor proyección social y territorial. Las consecuencias que tuvo su fundación son conocidas, pero no conviene confundirlas con las causas. Las dificultades para asegurar la continuidad de las lecturas públicas municipales parece apuntar a que la demanda social de este tipo de enseñanzas aún era débil en los años inmediatamente precedentes a la fundación. Por otro lado, cabe preguntarse si la poderosa personalidad de Rodrigo de Borja bastó para que se arrinconaran súbitamente las desconfianzas casi seculares que, después de dar al traste con los anteriores proyectos de colaboración, habían creado 
una distancia infranqueable entre el consell y la catedral en lo que a las políticas escolásticas tocaba. Para algunos historiadores la creación de la Universidad formó parte de los esfuerzos puestos en marcha para revertir la decadencia económica e institucional de la ciudad, cuyos síntomas comenzaban a resultar evidentes. Por último, cabe plantearse si, como parece indicar la prosopografía de los titulados en los primeros años, los dirigentes de la ciudad, clérigos y laicos, hicieron una evaluación de la demanda que trascendía la propia sociedad urbana valenciana, que en apariencia era la destinataria directa de los servicios de la institución, para dirigir su mirada hacia una clientela potencial más amplia, la del extenso hinterland que había sostenido durante el siglo XV la pujanza económica de Valencia, y que durante el siglo siguiente nutrió en buena medida de estudiantes el nuevo centro universitario. 